\title{
MISKLASIFIKASI MAHASISWA BARU F SAINTEK UIN SUNAN KALIJAGA JALUR TES TULIS DENGAN ANALISIS REGRESI LOGISTIK
}

\author{
Mohammad Farhan Qudratullah \\ Program Studi Matematika Fakultas Sains dan Teknologi \\ Universitas Islam Negeri Sunan Kalijaga Yogyakarta, Indonesia \\ e-mail: aching_lo@yahoo.com
}

\begin{abstract}
ABSTRAK
Pada tahun ajaran 2008/2009, UIN Sunan Kalijaga membuka 2 (dua) Jalur Penerimaan Mahasiswa Baru, yaitu Jalur Reguler yang meliputi Tes Tulis dan Seleksi (seleksi khusus dan mahasiswa berprestasi), serta Jalur SNMPTN. Selama ini, penerimaan mahasiswa baru melalui jalur tes tulis hanya berdasarkan pilihan saat mendaftar dan hasil ujian tulis tanpa mempertimbangkan variabel lain seperti nilai UAN/ UAS. Penelitian ini bertujuan untuk mengetahui variabel apa saja (nilai tes tulis dan nilai UAN/UAS) yang mampu membedakan karakteristik mahasiswa program studi yang satu dengan yang lainnya, sehingga memungkinkan untuk mengetahui besar tingkat misklasifikasi yang terjadi pada program studi cluster Sains Fakultas SAINTEK. Adapun alat analisis yang digunakan adalah analisis regresi logistik multinomial. Pada tingkat kepercayaan 90\% diperoleh bahwa dari 7 (tujuh) variabel independen yang digunakan, terdapat 5 (lima) variabel yang mampu membedakan karakteristik mahasiswa baru program studi yang satu dengan yang lainnya, yaitu nilai tes numerik (NT_Numerik), nilai tes spasial (NT_Spasial), nilai UAN Matematika (UANMAT), nilai UAS Fisika (UANFIS), dan nilai UAS Kimia (UASKIM), sedangkan 2 (dua) variabel lainnya yaitu: nilai tes verbal (NT_Verbal) dan nilai UAS Biologi (UASBIO) tidak signifikan. Misklasifikasi mahasiswa baru jalur tes cukup tinggi, yaitu mancapai 35,1\%. Misklasifikasi dari yang paling rendah berturut-turut adalah program studi Matematika 17,7\%, program studi Kimia 33,3\%, program studi Biologi 47,7\%, dan yang paling tinggi program studi Fisika mencapai 50\%. Sehingga proses penerimaan mahasiswa baru pada keempat program studi pada umumnya perlu mempertimbahkan nilai UAN/ UAS.
\end{abstract}

Kata Kunci: Analisis Regresi Logistik Multinomial, Mahasiswa Baru, Misklasifikasi

\section{PENDAHULUAN}

Di era globalisasi yang bercirikan high competition ini, tuntutan terhadap perguruan tinggi bukan hanya sebatas kemampuan untuk menghasilkan lulusan yang diukur secara akademik, melainkan keseluruhan program dari lembaga-lembaga perguruan tinggi tersebut harus mampu membuktikan kualitas yang tinggi demi terciptanya manusia Indonesia seutuhnya, yaitu menguasai ilmu pengetahuan dan teknologi (IPTEK), estetika (seni), moral dan etika.

Di Indonesia, tingkat human development index (HDI) yang mengukur pembandingan antara life expectancy, literacy, education, dan standard of living belum beranjak naik secara signifikan, rangking ini tidak berbeda jauh dengan negara Vietnam yang baru merdeka (tabel 1), sementara akses pendidikan bagi usia 19-24 tahun yang terdaftar sebagai mahasiswa di Indonesia juga belum menggembirakan yaitu sebesar 14 persen. Kondisi partisipasi untuk melanjutkan di perguruan tinggi ini masih rendah apabila dibandingkan dengan negara Malaysia (38 persen) atau Mesir (30 persen).

Universitas Islam Negeri (UIN) Sunan Kalijaga hadir untuk memenuhi tuntutan masyarakat dan dunia kerja terhadap lembaga pendidikan tinggi yang dapat mengintegrasikan keislaman dan keilmuan serta bermanfaat bagi peradaban. UIN Sunan Kalijaga diharapkan dapat menghasilkan pekerja yang profesional, intelektual yang agamis, dan pemimpin bangsa yang moralis.

Tabel 1. Posisi kualitas sumberdaya manusia tahun 1995, 2000, 2002, 2006 berdasarkan HDI.

\begin{tabular}{lcccc}
\hline \multirow{2}{*}{ Negara } & \multicolumn{4}{c}{ Tahun } \\
\cline { 2 - 5 } & $\mathbf{1 9 9 5}$ & $\mathbf{2 0 0 0}$ & $\mathbf{2 0 0 2}$ & $\mathbf{2 0 0 6}$ \\
\hline China & 111 & 99 & 96 & 81 \\
Thailand & 58 & 76 & 70 & 74 \\
Philipina & 100 & 77 & 77 & 84 \\
Malaysia & 59 & 61 & 59 & 61 \\
Indonesia & 104 & 109 & 110 & 108 \\
Vietnam & 120 & 108 & 109 & 109 \\
\hline
\end{tabular}

Sumber: UNDP berbagai edisi

Kehadiran UIN Sunan Kalijaga merupakan perjuangan panjang umat Islam Indonesia, yang dimulai sejak tahun 1951. Tranformasi IAIN Sunan Kalijaga menjadi UIN Sunan Kalijaga secara de jure, ditandai dengan terbitnya Keputusan Presiden RI Nomor 50 Tahun 2004 tertanggal 21 Juni 2004. Implikasinya dalam aspek akademik, UIN Sunan Kalijaga 
mendapatkan ijin penyelenggaraan program studi 'umum' di luar ilmu-ilmu keislaman yang ditandai dengan berdirinya 2 (dua) fakultas baru, yaitu Fakultas Sains dan Teknologi (F SAINTEK) yang terdiri atas 10 program studi, yaitu Matematika, Biologi, Kimia, Fisika, Pendidikan Matematika, Pendidikan Biologi, Pendidikan Kimia, Pendidikan Fisika, Teknologi Informasi, dan Teknologi Industri.dan Fakultas Ilmu Sosial dan Himanora (F ISOSHUM) yang terdiri atas 3 program studi yaitu Psikologi, Sosiologi, dan Ilmu Komunikasi.

Demi percepatan mewujudkan visi, misi, dan tujuan UIN Sunan Kalijaga sebagai center for excellence dalam bidang pengembangan keilmuaan dan keislaman yang integratifinterkonektif, UIN Sunan Kalijaga terus melakukan pembenahan diberbagai aspek. Salah satunya adalah Sistem Penerimaan Mahasiswa Baru dengan melakukan revisi dan penambahan jalur penerimaan mahasiswa baru yang mampu menjaring mahasiswa baru yang berkualitas dan mampu mengakomodir semua program studi yang semakin beragam. Pada tahun ajaran 2008/ 2009, UIN Sunan Kalijaga membuka 2 (dua) Jalur Penerimaan Mahasiswa Baru, yaitu Jalur Reguler yang meliputi Tes Tulis dan Seleksi (seleksi khusus dan mahasiswa berprestasi), serta Jalur SNMPTN.

Jalur tes tulis diadakan sendiri oleh UIN Sunan Kalijaga yang merupakan tes potensi akademik yang meliputi tes verbal, tes numerik, dan tes spasial. Mahasiswa baru yang diterima adalah sejumlah mahasiswa yang dirangking berdasarkan hasil penjumlahan nilai ketiga tes tersebut yang disesuaikan dengan pilihannya. Dengan kata lain, penerimaan mahasiswa baru hanya berdasarkan hasil ujian tulis tanpa mempertimbangkan prestasi akademik lainnya seperti nilai UAN/ UAS. Serta belum diketahui apakah mahasiswa yang diterima telah masuk program studi yang sesuai atau tidak. Penelitian ini akan mengidentifikasi faktor-faktor apasaja yang dapat dijadikan kriteria bahwa seorang mahasiswa telah masuk program studi yang sesuai dengan pilihannya atau tidak.

Penelitian ini bertujuan untuk mengetahui nilai-nilai apa saja (nilai tes tulis dan nilai UAN/UAS) yang membedakan karakteristik mahasiswa program studi yang satu dengan yang lainnya pada F SAINTEK, khususnya program studi cluster Sains (Matematika, Biologi, Kimia, dan Fisika), dan mendeteksi mahasiswamahasiswa yang kemungkinan memiliki karakteristik yang berbeda atau kemungkinan salah memilih program studi (misklasifikasi). Sehingga hasil penelitian ini dapat dijadikan bahan evaluasi dalam sistem penerimaan mahasiswa baru UIN Sunan Kalijaga, khususnya yang akan masuk pada program studi-program studi di F SAINTEK yang jelas memiliki karakteristik berbeda dengan program studi yang lainnya.

Alat statistika yang akan digunakan adalah analisis regresi logistik dan data yang digunakan adalah data mahasiswa baru 4 (empat) program studi Sains (Matematika, Biologi, Kimia, dan Fisika) angkatan 2008/ 2009 yang diterima melalui Jalur Tes Tulis yang meliputi nilai tes potensi akademik (tes verbal, tes numerik, dan tes spasial) dan nilai UAN/ UAS untuk matapelajaran MIPA (Matematika, Biologi, Kimia, dan Fisika).

\section{ANALISIS REGRESI LOGISTIK}

Analisis regresi logistik merupakan salah satu alat analisis dalam statistika yang merupakan bentuk khusus dari analisis regresi, yaitu variabel dependennya merupakan data skala nominal atau ordinal, sedangkan variabel independennya dapat berbentuk nominal, ordinal, skala, ataupun rasio. Dinamakan regresi logistik, karena analisis regresi ini pembentukan modelnya didasarkan atas kurva logistik. Nilai yang dihasilkan persamaan regresi logistik merupakan peluang kejadian yang digunakan sebagai ukuran untuk pengklasifikasian. Jika variabel dependen terdiri atas 2 (dua) klasifikasi, maka disebut analisis regresi logistik biner. Dan jika variabel dependen terdiri atas 3 (tiga) klasifikasi atau lebih, maka disebut analisis regresi logistik multinomial.

\section{Model Regresi Logistik}

Misalkan terdapat $n$ hasil pengamatan $\left(y_{i} ; x_{i 1} ; x_{i 2} ; \ldots ; x_{i p}\right)$, dengan $y_{i}$ adalah variabel dependen yang dikotomi/biner subjek ke-i yang diberi kode 0 atau 1 dan $x_{i k}$ adalah variabel independen subjek ke- $i$ sejumlah $p$ variabel, $i=1$, $2, \ldots, n$. Maka model regresi logistik dapat ditulis:

$$
\pi(x)=\frac{\exp \left(\beta_{0}+\sum_{k=1}^{p} \beta_{k} x_{i k}\right)}{\left(1+\exp \left(\beta_{0}+\sum_{k=1}^{p} \beta_{k} x_{i k}\right)\right)}
$$

dimana $\pi(x)=E(y \mid x)$

Dengan melakukan transformasi logit,

$$
g(x)=\ln \left(\frac{\pi(x)}{1-\pi(x)}\right)
$$

diperoleh suatu fungsi penghubung untuk model regresi logistik berikut:

$$
g(x)=\ln \left(\frac{\pi(x)}{1-\pi(x)}\right)
$$




$$
\begin{aligned}
g(x) & =\ln \left(\frac{\frac{\exp \left(\beta_{0}+\sum_{k=1}^{p} \beta_{k} x_{i k}\right)}{\left(1+\exp \left(\beta_{0}+\sum_{k=1}^{p} \beta_{k} x_{i k}\right)\right)}}{1}\right) \\
& =\beta_{0}+\sum_{k=1}^{p} \beta_{k} x_{i k}
\end{aligned}
$$

Model regresi logistik multinomial merupakan perluasan dari model regresi logistik biner, misalkan variabel dependen terdiri atas 3 (tiga) kategori maka variabel dependen $y$ dapat diberi kode 0,1 , atau 2, dimana $y=0$ merupakan kategori acuan. Pada model regresi logistik biner terdapat 1 (satu) fungsi logit $\mathrm{y}=1$ terhadap $\mathrm{y}=0$, maka pada model regresi logistik multinomial 3 (tiga) kategori terdapat 2 (dua) fungsi logit, yaitu fungsi logit $y=1$ terhadap $y=0$ dan fungsi logit $y$ $=2$ terhadap $y=0$.

Misalkan $\pi_{j}(x)=P(y=j \mid x)$ dimana $\mathrm{j}=0$, 1, 2 dan mengikuti kaidah pada model regresi logistik biner, maka kedua fungsi logit dapat dirumuskan berikut:

$$
\begin{aligned}
& g_{1}(x)=\ln \left(\frac{\pi_{1}(x)}{\pi_{0}(x)}\right)=\ln \left(\frac{P(y=1 \mid x)}{P(y=0 \mid x)}\right) \\
& =\ln \left(\frac{\frac{\exp \left(\beta_{01}+\sum_{k=1}^{p} \beta_{k 1} x_{i k}\right)}{\left(1+\exp \left(\beta_{01}+\sum_{k=1}^{p} \beta_{k 1} x_{i k}\right)\right)}}{1}\right) \\
& =\beta_{01}+\sum_{k=1}^{p} \beta_{k 1} x_{i k} \\
& g_{2}(x)=\ln \left(\frac{\pi_{2}(x)}{\pi_{0}(x)}\right)=\ln \left(\frac{P(y=2 \mid x)}{P(y=0 \mid x)}\right) \\
& =\ln \left(\frac{\frac{\exp \left(\beta_{02}+\sum_{k=1}^{p} \beta_{k 2} x_{i k}\right)}{\left(1+\exp \left(\beta_{02}+\sum_{k=1}^{p} \beta_{k 2} x_{i k}\right)\right)}}{1}\right) \\
& =\beta_{02}+\sum_{k=1}^{p} \beta_{k 2} x_{i k}
\end{aligned}
$$

Sehingga diperoleh:

$$
\begin{aligned}
P(y=1 \mid x) & =\pi_{1}(x) \\
& =P(y=0 \mid x) \cdot \exp \left(\beta_{01}+\sum_{k=1}^{p} \beta_{k 1} x_{i k}\right) \\
P(y=2 \mid x) & =\pi_{2}(x) \\
& =P(y=0 \mid x) \cdot \exp \left(\beta_{02}+\sum_{k=1}^{p} \beta_{k 2} x_{i k}\right)
\end{aligned}
$$

Karena $\pi_{0}(x)+\pi_{1}(x)+\pi_{1}(x)=1$, maka dapat ditulis

$$
\begin{aligned}
& \pi_{0}(x)= \\
& \frac{1}{1+\exp \left(\beta_{01}+\sum_{k=1}^{p} \beta_{k 1} x_{i k}\right)+\exp \left(\beta_{02}+\sum_{k=1}^{p} \beta_{k 2} x_{i k}\right)}
\end{aligned}
$$

$$
\begin{aligned}
& \pi_{1}(x)= \\
& \frac{\exp \left(\beta_{01}+\sum_{k=1}^{p} \beta_{k 1} x_{i k}\right)}{1+\exp \left(\beta_{01}+\sum_{k=1}^{p} \beta_{k 1} x_{i k}\right)+\exp \left(\beta_{02}+\sum_{k=1}^{p} \beta_{k 2} x_{i k}\right)}
\end{aligned}
$$

$$
\begin{aligned}
& \pi_{2}(x)= \\
& \frac{\exp \left(\beta_{02}+\sum_{k=1}^{p} \beta_{k 2} x_{i k}\right)}{1+\exp \left(\beta_{01}+\sum_{k=1}^{p} \beta_{k 1} x_{i k}\right)+\exp \left(\beta_{02}+\sum_{k=1}^{p} \beta_{k 2} x_{i k}\right)}
\end{aligned}
$$

Berdasarkan hasil di atas, dapat digeneralisasikan (J-1) model regresi logistik multinomial untuk variabel independen terdiri atas J kategori adalah:

$$
\pi_{j}(x)=\frac{\exp \left(\beta_{0 j}+\sum_{k=1}^{p} \beta_{k j} x_{i k}\right)}{1+\sum_{j=1}^{J-1} \exp \left(\beta_{0 j}+\sum_{k=1}^{p} \beta_{k j} x_{i k}\right)}
$$

Dan fungsi logitnya adalah:

$$
\begin{aligned}
g_{j}(x) & =\ln \left(\frac{\pi_{j}(x)}{\pi_{0}(x)}\right)=\beta_{0 j}+\sum_{k=1}^{p} \beta_{k j} x_{i k} \\
\operatorname{dimana} \mathrm{j} & =1,2, \ldots, \mathrm{J}-1
\end{aligned}
$$

\section{METODE DAN TEKNIK ANALISIS}

\section{Estimasi Parameter}

Penaksiran parameter pada model regresi logistik dapat mengunakan metode Maksimum Likelihood Estimator (MLE). Dengan menetapkan asumsi distribusi binomial dan setiap objek pengamatan saling independen, fungsi likelihood metode MLE merupakan fungsi linear maka untuk memperoleh taksiran parameter dilakukan proses iterasi dengan metode Newton-Raphson, dengan menentukan nilai awal dari $\beta$, yaitu $\beta^{0}$.

Estimasi maksimum likelihood merupakan pendekatan dari estimasi Weighted Least Square, dimana matrik pembobotnya berubah setiap iterasi. Proses menghitung estimasi maksimum likelihood ini disebut juga sebagai Iteratif Reweighted Least Square.

\section{Uji Serentak}

Dalam uji serentak ini, digunakan likelihood-rasio test, metode ini merupakan metode pengujian model dengan membandingkan likelihood untuk model lengkap $\left(\mathrm{L}_{1}\right)$ dan likelihood untuk model yang semua parameternya sama dengan nol $\left(\mathrm{L}_{0}\right)$.

$\mathrm{H}_{0}: \beta_{1}=\beta_{2}=\cdots=\beta_{p}=0$

$\mathrm{H}_{1}$ : minimal ada satu $\beta_{j} \neq 0, j=1,2, \ldots, p$ 
Statistik uji yang digunakan adalah:

$$
G^{2}=-2 \ln \left(\frac{L_{0}}{L_{1}}\right)
$$

Pada tingkat kepercayaan $(1-\alpha) \%, \mathrm{H}_{0}$ ditolak jika $G^{2}>\chi_{(\alpha, d f)}^{2}$ atau P-value (sig.) $<\alpha$.

\section{Uji Parsial}

Uji parsial untuk menguji signifikasi setiap parameter dalam model yang dapat dilakukan dengan Wald Test. Uji ini dilakukan untuk mengetahui apakah setiap variabel independen dapat diandalkan membangun model atau tidak dalam proses pengklasifikasian.

$$
\begin{aligned}
& \mathrm{H}_{0}: \beta_{j}=0 \\
& \mathrm{H}_{1}: \beta_{j} \neq 0
\end{aligned}
$$

untuk $\mathrm{j}=1,2, \ldots, p$

Statistik uji yang digunakan adalah:

$$
W^{2}=\frac{\beta_{j}^{2}}{\left(S E\left(\beta_{j}\right)\right)^{2}}
$$

Pada tingkat kepercayaan $(1-\alpha) \%, \mathrm{H}_{0}$ ditolak jika $W^{2}>\chi_{(\alpha, d f)}^{2}$ atau P-value (sig.) $<\alpha$.

\section{Uji Kesesuaian Model}

Uji kesesuaian model regresi logistik yang digunakan adalah chi-square test.

$$
\begin{aligned}
& \mathrm{H}_{0} \text { : model sesuai } \\
& \mathrm{H}_{1} \text { : model tidak sesuai }
\end{aligned}
$$

Statistik uji yang digunakan adalah:

$$
\chi^{2}=\sum_{j=1}^{g} \frac{\left(O_{j}-n_{j} \bar{\pi}_{j}\right)^{2}}{n_{j} \bar{\pi}_{j}\left(1-\bar{\pi}_{j}\right)}
$$

Pada tingkat kepercayaan $(1-\alpha) \%, \mathrm{H}_{0}$ ditolak jika $\chi^{2}>\chi_{(\alpha, d f)}^{2}$ atau P-value (sig.) $<\alpha$.

\section{Evaluasi Model}

Evaluasi fungsi klasifikasi (fungsi logistik) dilakukan dengan membuat tabulasi antara actual group dan predicted group yang diperoleh dari fungsi logistik. Selanjutnya dihitung proporsi pengamatan yang benar klasifikasinya, diharap- kan proporsi pengamatan yang benar diklasifikasikan tersebut sebesar mungkin atau proporsi pengamatan yang salah sekecil mungkin.

\section{Data dan Variabel}

Data yang digunakan adalah data mahasiswa baru jalur tes tulis tahun ajaran 2008/ 2009 Fakultas Sains dan Teknologi UIN Sunan Kalijaga yang bersumber pada bagian akademik Fakultas Sains dan Teknologi dan DAPIC Teknologi UIN Sunan Kalijaga yang terdiri atas 58 mahasiswa dengan perincian 12 mahasiswa program studi Matematika, 6 mahasiswa program studi Fisika, 22 mahasiswa program studi Kimia, dan 15 mahasiswa program studi Biologi.

Sesuai tujuan penelitian ini, maka variabel dependennya adalah variabel kelompok yaitu variabel yang berupa kategori program studi yang terdiri dari Matematika (MAT) dengan kode 1, Fisika (FIS) dengan kode 2, Kimia(KIM) dengan kode 3, dan Biologi(BIO) dengan kode 4 . Selanjutnya variabel independen yang digunakan dalam penelitian ini ada 7 (tujuh) variabel, yaitu:

1. NT_Verbal : Nilai hasil Ujian Tulis yakni tes verbal

2. NT_Numerik : Nilai hasil Ujian Tulis yakni tes Numerik

3. NT_Spasial : Nilai hasil Ujian Tulis yakni tes Spasial

4. UANMAT : Nilai UAN bidang studi Matematika

5. UASBIO : Nilai UAS bidang studi Biologi

6. UASKIM : Nilai UAS bidang studi Kimia

7. UASFIS : Nilai UAS bidang studi Fisika

\section{HASIL DAN PEMBAHASAN}

Berikut adalah hasil analisis data yang proses analisisnya mengunakan bantuan software SPSS.15.0:

Tabel 1. Hasil Likelihood Rasio Test tahap awal

\begin{tabular}{lcccc}
\hline \multicolumn{1}{c}{ Model } & Chi-Kuadrat & df & Sig & Keterangan \\
\hline $\begin{array}{l}\text { Keseluruhan } \\
\text { Pervariabel }\end{array}$ & $\mathbf{5 7 , 9 0 2}$ & $\mathbf{2 1}$ & $\mathbf{0 , 0 0 0}$ & Signifikan \\
1. NT_Verbal & 0,836 & 3 & 0,841 & Tidak Signifikan \\
2. NT_Numerik & 19,869 & 3 & 0,000 & Signifikan \\
3. NT_Spasial & 9,444 & 3 & 0,024 & Signifikan \\
4. UANMAT & 12,950 & 3 & 0,005 & Signifikan \\
5. UASFIS & 11,133 & 3 & 0,011 & Signifikan \\
6. UASKIM & 8,372 & 3 & 0,039 & Signifikan \\
7. UASBIO & 3,015 & 3 & 0,389 & Tidak Signifikan \\
\hline
\end{tabular}


Tabel 2. Hasil Likelihood Rasio Test tahap akhir

\begin{tabular}{lcccc}
\multicolumn{1}{c}{ Model } & Chi-Kuadrat & df & Sig & Keterangan \\
\hline $\begin{array}{l}\text { Keseluruhan } \\
\text { Pervariabel }\end{array}$ & $\mathbf{6 1 , 6 9 0}$ & $\mathbf{1 5}$ & $\mathbf{0 , 0 0 0}$ & Signifikan \\
1. NT_Numerik & & 3 & 0,000 & Signifikan \\
2. NT_Spasial & & 3 & 0,010 & Signifikan \\
3. UANMAT & & 3 & 0,001 & Signifikan \\
4. UASFIS & & 3 & 0,012 & Signifikan \\
5. UASKIM & 3 & 0,078 & Signifikan \\
\hline
\end{tabular}

Langkah awal dalam proses ini adalah memasukan semua variabel independen kedalam model dan ringkasan hasilnya disajikan dalam tabel 1. Pada tabel 1 disajikan hasil uji serentak atau uji keseluruhan dari model, tampak bahwa nilai sig. $=0,000<0,10$ yang berarti Ho ditolak, yaitu minimal ada satu $\beta_{p} \neq 0$. Kemudian untuk pervariabel, tampak bahwa pada tingkat kepercayaan $90 \%$ terdapat 2 (dua) variabel independen tidak signifikan yaitu NT_Verbal dan
UASFIS, maka perlu dilakukan analisis ulang dengan mengeluarkan variabel independen yang tidak signifikan (sig. $<0,10$ ) satu demi satu dari model, mulai dari NT_Verbal dan diperoleh bahwa UASFIS masih belum signifikan sehingga harus dikeluarkan dari model dan ringkasannya disajikan dalam tabel 2, tampak bahwa semua variabel independen telah signifikan sehingga proses analisis selanjutnya, yaitu uji parsial mengunakan Wald test.

Tabel 3. Hasil estimasi parameter tahap akhir

\begin{tabular}{llcccccc}
\hline \multicolumn{1}{c}{ Variabel } & B & Wald & df & Sig & Exp(B) & Keterangan \\
\hline MAT & 0. Intercept & $-13,061$ & 2,861 & 1 & 0,091 & & \\
& 1. NT_Numerik & 0,542 & 5,763 & 1 & 0,016 & 1,720 & Signifikan \\
& 2. NT_Spasial & $-0,184$ & 0,236 & 1 & 0,627 & 0,832 & Tidak Signifikan \\
& 3. UANMAT & 1,589 & 7,202 & 1 & 0,007 & 4,900 & Signifikan \\
& 4. UASFIS & $-0,371$ & 0,299 & 1 & 0,585 & 0,690 & Tidak Signifikan \\
& 5. UASKIM & $-1,273$ & 3,636 & 1 & 0,057 & 0,280 & Signifikan \\
\hline FIS & 0. Intercept & $-2,561$ & 0,167 & 1 & 0,683 & & \\
& 1. NT_Numerik & $-0,376$ & 4,670 & 1 & 0,031 & 0,687 & Signifikan \\
& 2. NT_Spasial & 1,168 & 5,357 & 1 & 0,021 & 3,217 & Signifikan \\
& 3. UANMAT & 2,274 & 5,969 & 1 & 0,015 & 9,714 & Signifikan \\
& 4. UASFIS & $-1,796$ & 5,258 & 1 & 0,022 & 0,166 & Signifikan \\
& 5. UASKIM & $-1,021$ & 3,58 & 1 & 0,076 & 0,360 & Signifikan \\
\hline KIM & 0. Intercept & 5,103 & 2,342 & 1 & 0,126 & & \\
& 1. NT_Numerik & $-0,047$ & 0,407 & 1 & 0,524 & 0,955 & Tidak Signifikan \\
& 2. NT_Spasial & 0,269 & 1,732 & 1 & 0,188 & 1,308 & Tidak Signifikan \\
& 3. UANMAT & 0,584 & 2,052 & 1 & 0,152 & 1,793 & Tidak Signifikan \\
& 4. UASFIS & $-1,084$ & 6,101 & 1 & 0,014 & 0,338 & Signifikan \\
& 5. UASKIM & $-0,402$ & 1,249 & 1 & 0,264 & 0,669 & Tidak Signifikan \\
\hline BIO sebagai kelompok acuan & & & & & & \\
\hline
\end{tabular}

Berdasarkan nilai koefisien dari tabel 3 di atas, dapat disusun 3 (tiga) fungsi logit, yaitu:

1. Fungsi logit program studi Matematika dengan Biologi sebagai acuan

$$
\begin{aligned}
& g_{1}(x)=-13,061+0,542 . N T \_N u m e r i k^{*}-0,184 . N T \_S p a s i a l+1,589 . \text { UANMAT }^{*} \\
& -0,371 . \text { UASFIS - 1,273.UASKIM* }
\end{aligned}
$$

2. Fungsi logit program studi Fisika dengan Biologi sebagai acuan

$$
\begin{aligned}
g_{2}(x)= & -2,561-0,376 . N T \_ \text {Numerik }^{*}+1,168 . \text { NT_Spasial }^{*}+2,274 . \text { UANMAT }^{*} \\
& -1,796 . \text { UASFIS* }^{*} \text { 1,021.UASKIM }
\end{aligned}
$$

3. Fungsi logit program studi Kimia dengan Biologi sebagai acuan

$$
\begin{aligned}
g_{3}(x)= & 5,103-0,047 . N T \_N u m e r i k+0,296 . N T \_S p a s i a l+0,584 . U A N M A T \\
& -1,084 . U A S F I S^{*}-0,402 . U A S K I M
\end{aligned}
$$

Ket: * signifikan pada tingkat kepercayaan $90 \%$ 
Tampak bahwa pada tingkat kepercayaan 90\% terdapat 3 (tiga) variabel independen yang membedakan mahasiswa yang memilih program studi Matematika dan Biologi, yaitu NT_Numerik, UANMAT, dan UASKIM. Nilai tes numerik dan nilai UAS Matematika mahasiswa program studi Matematika cenderung lebih tinggi, sedangkan nilai UAS Kimianya cenderung lebih rendah dibanding program studi Biologi.

Kemudian yang membedakan program studi Fisika dan Biologi adalah 5 (lima) variabel independen (NT_Numerik, NT_Spasial, UANMAT, UASFIS, dan UASKIM). Nilai ujian tes spatial, UAN Matematika mahasiswa program studi Fisika cenderung lebih tinggi, sedangkan nilai tes numerik UAS Fisika dan UAS Kimia cenderung lebih rendah dibanding program studi Biologi. Selanjutnya yang membedakan mahasiswa program studi Kimia dan program studi Biologi hanya satu variabel independen, yaitu UASFIS. Nilai UAS Fisika mahasiswa program studi kimia cenderung lebih rendah dibanding program studi Biologi.

Dari uraian di atas dapat dikembangkan dan disusun variabel-variabel independen yang membedakan karakteristik mahasiswa antara program studi yang selengkapnya disajikan dalam tabel 4 berikut:

Tabel 4. Karakteristik 4 (empat) program studi

\begin{tabular}{|c|c|c|c|}
\hline & & PROGRAM STU & \\
\hline & FIS & KIM & BIO \\
\hline MAT & NT_Numerik (+/-) & NT_Numerik (+/-) & NT_Numerik (+/-) \\
\hline & NT_Spasial $(-/+)$ & NT_Spasial $(-/+)$ & UANMAT $(+/-)$ \\
\hline & UASFIS $(+/-)$ & UANMAT $(+/-)$ & UASKIM $(-/+)$ \\
\hline & & UASFIS (+/-) & \\
\hline & & $\operatorname{UASKIM}(-/+)$ & \\
\hline FIS & & NT_Numerik $(-/+)$ & NT_Numerik $(-/+)$ \\
\hline & & NT_Spasial (+/-) & NT_Spasial (+/-) \\
\hline & & UANMAT $(+/-)$ & UANMAT (+/-) \\
\hline & & UASKIM $(-/+)$ & UASFIS $(-/+)$ \\
\hline & & & $\operatorname{UASKIM}(-/+)$ \\
\hline KIM & & & UASFIS $(-/+)$ \\
\hline
\end{tabular}

+/- : program studi pada baris nilainya > program studi pada kolom

$-/+$ : program studi pada baris nilainya $<$ program studi pada kolom

Tabel 5 merupakan ringkasan uji kesesuaian model mengunakan uji Chi-Kuadrat, tampak bahwa nilai Sig. $=0,995>0,10$, artinya pada tingkat kepercayaan $90 \%$ Ho tidak ditolak atau dengan kata lain model sesuai dan dapat digunakan

Tabel 5. Hasil uji kesesuaian model

\begin{tabular}{lcccc}
\hline & $\begin{array}{c}\text { Chi- } \\
\text { Kuadrat }\end{array}$ & df & Sig & Keterangan \\
\hline Pearson & 111,564 & 153 & 0,995 & Model Sesuai \\
Deviance & 84,291 & 153 & 1,000 & Model Sesuai \\
\hline
\end{tabular}

Sedangkan untuk mengevaluasi fungsi logistik, dari tabel 6 dapat dilihat bahwa 2 atau 16,7\% mahasiswa Matematika diprediksi masuk dalam program studi lain dalam hal ini Kimia, 3 atau 50\% mahasiswa Fisika diprediksi masuk program studi lain, yaitu Kimia, 8 atau 33,3\% mahasiswa program studi Kimia diprediksi masuk program studi lain, yaitu 2 program studi Matematika, 1 program studi Fisika, dan 5 program studi Biologi, terakhir 7 atau $47,7 \%$ mahasiswa program studi Biologi diprediksi masuk program studi lain, yaitu 1 program studi Matematika, 2 program studi Fisika, dan 4 program studi Kimia. Secara keseluruhan dari 58 mahasiswa baru F SAINTEK yang diterima melalui ujian tulis terdapat 20 mahasiswa atau
$35,1 \%$ yang misklasifikasi dalam pemilihan program studi, misklasifikasi terbesar adalah program studi Fisika dan diikuti program studi Biologi.

Tabel 6. Hasil pengklasifikasian model

\begin{tabular}{lccccc} 
& \multicolumn{3}{c}{ Prediksi } & \multicolumn{1}{c}{ \% Kebenaran } \\
\cline { 2 - 6 } Data Aktual & MAT & FIS & KIM & BIO & Prediksi \\
\hline MAT & 10 & 0 & 2 & 0 & 83,3 \\
FIS & 0 & 3 & 3 & 0 & 50,0 \\
KIM & 2 & 1 & 16 & 5 & 66,7 \\
BIO & 1 & 2 & 4 & 8 & 53,3 \\
\hline \multicolumn{1}{c}{ \% Kebenaran Prediksi (Keseluruhan) } & $\mathbf{6 4 , 9}$
\end{tabular}

\section{PENUTUP}

Dari uraian analisis data dan pembahasan di atas dapat ditarik beberapa kesimpulan sebagai berikut:

1. Pada tingkat kepercayaan $90 \%$ dari 7 (tujuh) variabel independen yang digunakan, terdapat 5 (lima) variabel yang mampu membedakan karakteristik mahasiswa baru program studi yang satu dengan yang lainnya pada program studi cluster sains Fakultas SAINTEK, yaitu nilai tes numerik (NT_Numerik), nilai tes spasial (NT_Spasial), nilai UAN Matematika (UANMAT), nilai UAS 
Fisika (UANFIS), dan nilai UAS Kimia (UASKIM), sedangkan 2 (dua) variabel lainnya yaitu: nilai tes verbal (NT_Verbal) dan nilai UAS Biologi (UASBIO) tidak signifikan.

2. Misklasifikasi mahasiswa baru jalur tes tulis 2008/ 2009 pada program studi cluster sains Fakultas SAINTEK cukup tinggi, yaitu mancapai $35,1 \%$. Misklasifikasi dari yang paling rendah berturut-turut adalah program studi Matematika 17,7\%, program studi Kimia $33,3 \%$, program studi Biologi $47,7 \%$, dan yang paling tinggi program studi Fisika mencapai $50 \%$. Sehingga proses penerimaan mahasiswa baru pada keempat program studi pada umumnya perlu mempertimbahkan nilai UAN/ UAS.

Adapun beberapa saran untuk penelitian selanjutnya, yaitu:

1. Pada penelitian ini program studi yang diteliti adalah program studi yang masuk dalam cluster sains di Fakultas SAINTEK. Penelitian ini dapat diperluas dengan melibatkan semua program studi di Fakultas SAINTEK maupun semua Fakultas serta penelitian bukan hanya melibatkan satu angkatan tapi beberapa angkatan.

2. Variabel independen yang digunakan adalah nilai-nilai sebelum mahasiswa ikut perkuliahan, yaitu nilai tes tulis tulis (nilai tes verbal, nilai tes numerik, nilai tes spasial) dan nilai UAN/ UAS (Matematika, Fisika, Kimia, Biologi). Variabel independen ini dapat diperluas dengan mempertimbangkan nilai matakuliah dasar pada semester awal, IPK, jalur masuk, dan lain sebagainya.

3. Untuk menganalisis misklasifikasi mahasiswa baru dapat juga mengunakan alat statistika lain seperti Analisis Diskriminan, Struktur Equation Modeling (SEM), maupun mengunakan Jaringan Syaraf Tiruan (JST)

\section{DAFTAR PUSTAKA}

[1] Agresti, A. (2007). An Introduction to Categorical Data Analysis, Second Edition. New Jersey: John Wiley \& Sons, Inc.

[2] Chatterjee, S. and Hadi, A.S. (2006). Regreeion Analysis by Example, Fourth Edition. New Jersey: John Willey \& Sons, Inc.

[3] Hosmer, D.W. and Lamenshow (1989). Applied Logistic Regression. New York: Willey and Sons.

[4] Kleinbaum, D.G. (1994). Logistic Regression. Springer-Verlag, New York.

[5] UIN Sunan Kalijaga (2004). Kerangka Dasar Keilmuan \& Pengembangan Kurikulum UIN. Yogyakarta: Pokja Akademik UIN Sunan Kalijaga

[6] UIN Sunan Kalijaga (2007). Sistem Penerimaan Mahasiswa Baru Tahun Ajaran 2008/ 2009 UIN Sunan Kalijaga. Yogyakarta: Pokja Akademik UIN Sunan Kalijaga. 